\title{
INVESTIGACIONES
}

\section{La cuestión del hiyab en las aulas. ¿Un caso de conflicto intercultural?*}

\author{
The issue of the Hiyab inside classrooms. \\ A case of an intercultural conflict?
}

\author{
Francisco Checa y Olmos $^{1}$ \\ Universidad de Almería. \\ fcheca@ual.es
}

\section{RESUMEN}

Todo lo que en Occidente rodea al hiyab -vestido islámico- se está analizando como una cuestión que va más allá de una simple prenda de vestir. Es examinada siempre como una representación y signo religiosos, que causan mucha desconfianza entre los occidentales. De hecho, la presencia del velo en las mujeres musulmanas siempre ha sido tema central dentro del debate feminista contemporáneo. Visto así, el cuerpo de las mujeres musulmanas -esto es, si ha de ser o no cubierto- parece encarnar hoy el lugar de tensión entre las representaciones de la modernidad y la que otros llaman la anti-modernidad. En este panorama sociocultural, hemos de preguntarnos cómo las mujeres musulmanas inmigradas están viviendo en los países occidentales la polémica del hiyab, dado que en ellas se produce la confluencia Oriente/Occidente.

Como no hay una investigación seria y global en el mundo islámico, ni fuera de este, que estudie las razones que llevan a las mujeres a velarse, este artículo, fruto de una investigación en marcha, recoge una investigación etnográfica en Almería (España), dando la palabra a las mujeres. La investigación se centra en jóvenes universitarias. Primero, porque conforman la élite de sus comunidades de inmigradas, segundo, porque se les supone un grado de formación académica y universitaria, tercero, porque la inmensa mayoría de las jóvenes que nos están llegando a la universidad española o han nacido en España o migraron con sus padres cuando eran muy pequeñas, cuarto, se están educando en un ambiente universitario que es democrático, laico, crítico y de libertad y, quinto, se supone que serán futuras profesionales que superarán el estatus socioeconómico de sus padres.

Palabras claves: Islam, hiyab, mujeres, inmigración, integración social.

\section{ABSTRACT}

Everything surrounding the hiyab-Islamic veil- in the western world is being analysed as an issue going beyond a simple item of clothing. It is always examined as a representation of some religious symbols, causing a considerable mistrust among the western culture. In fact, the presence of this veil on Muslim women has always been placed as the central theme in the contemporary feminist debate. The body of Muslim women -this means, whether it should be covered or not- seems to embody nowadays the fireplace between the representations of modernity and what others tend to call anti-modernity. Within this context, it would be appropriate to wonder how Muslim women who have immigrated to western countries - and located in this convergence point- are dealing with all this controversy around wearing the veil or hiyab.

\footnotetext{
* Agradecimientos al Proyecto REDES N 170039, Migration research based on Human Rights approach: Comparative studies between Chile, Mexico and Spain del programa de Cooperación Internacional financiados por la Comisión Nacional de Ciencia y Tecnología de Chile CONICYT (2017-2020).

1 Laboratorio de Antropología Social y Cultural. Centro de Estudio para las Migraciones y las Relaciones Interculturales, CEMyRI.
} 
As there is not to this day a serious and global research in the Islamic world that studies the precise reasons why women do wear the veil, this article, as the result of an investigation in process, pretends to give voice to these women. This research is focus on young university students. There are some reasons for that: Firstly, they exemplify the elite of their communities or immigrant colonies. They have reached to higher education studies overcoming a several academic failure among their compatriots, which can be also women. Secondly, they are required to have a reasonable academic and personal background which will lead them to a higher professional level. Thirdly, the vast majority of these young women who studies at Spanish Universities were born in Spain or has migrated with their parents when they were very young. Fourthly, they have been educated in a western educational system: secular, democratic, and critical in a free environment. And finally, after their studies they are supposed to obtain a higher professional level, surpassing the socioeconomic status of their parents and siblings.

Key words: Islam, hiyab, women, inmigration, social integration.

\section{INTRODUCCIÓN}

El panorama sociocultural que la inmigración está dibujando en la Europa del siglo XXI tiene poco que ver con las tres o cuatro últimas décadas del siglo pasado. España no es ajena a esta realidad. El cambio cultural va más de prisa de lo que los autóctonos aceptan o se imaginan. Y en los movimientos migratorios, es decir, contra las minorías étnicas, es contra quienes se reproducen todos los males y el caldo ideológico que hace prosperar a los partidos radicales de la extrema derecha, actualmente muy bien instalados en los países occidentales, sin importar que en esos mismos países no hace mucho eran gobernados por partidos socialistas o socialdemócratas. En los pilares de sus ideologías fascistoides está la inmigración como chivo expiatorio.

Por su parte, entre las minorías cultuales emigradas, o de origen inmigrado, no es fácil que se produzca una rápida asimilación, dado que los aspectos culturales de sus sociedades de origen, tan arraigados a los sentimientos, como son la alimentación, la indumentaria y muy especialmente la religión -y sus preceptos- son tan profundos que presentan procesos de resistencia y resignificación, antes que acogerse a un abandono total en destino y abrazar la cultura mayoritaria. La mochila cultural previa pesa y no pueden desprenderse de ella fácilmente, aunque quisieran. Tampoco defiendo que esta postura sea la solución deseada.

Este mantenimiento de la cultura de origen (a veces incluso en las segundas y terceras generaciones de origen inmigrado) es razón suficiente para que muchos nacionales duden del valor -e intenciones- de la integración social de estos colectivos. La religión, en mayor grado el islam, suele acaparar todas las críticas y los miedos.

Ahora bien, como se sabe, para las personas creyentes su religión es un asidero que suele ofrecerles paz, equilibrio emocional, compañía grupal, identidad, empatía con quienes profesan unas mismas creencias, etc., si cabe mucho más en las experiencias migratorias. Y los musulmanes en esto no van a ser una excepción.

Es en este ámbito de religión como asidero -o religión como generadora de identidaden el que la indumentaria tradicional de muchas mujeres musulmanas, el hiyab en este caso no debería extrañar a nadie, aunque se vistan así en un país donde la religión islámica no es la mayoritaria ni oficial.

Otra cosa bien diferente es que todo lo que rodea al hiyab en Occidente se está analizando como una cuestión que va más allá de una simple prenda de vestir. Es examinada siempre como una representación y signo religiosos, que causan mucha desconfianza entre 
los occidentales (véanse Amorós 2009; Checa y Olmos et al., 1999; García et al., 2012; Serrano, 2011; Checa, 2019).

De hecho, la presencia del velo en las mujeres musulmanas siempre ha sido tema central dentro del debate feminista contemporáneo. Desde ahí se expresa el corazón del conflicto entre dos visiones antinómicas: la del discurso neoorientalista (con un islamismo tradicionalista mayoritario) y la visión del discurso neooccidental hegemónico (la mujer se vela obligada por los varones) (véanse Tamayo 2009; Dassetto y Bastenier, 1984). Visto así, pues, el cuerpo de las mujeres musulmanas -esto es, si ha de ser o no cubierto- parece encarnar hoy el lugar de tensión entre las representaciones de la modernidad y la que otros llaman la anti-modernidad (García et al., 2012)2 .

En este panorama sociocultural, me parece acertado preguntarnos cómo las mujeres musulmanas inmigradas están viviendo en los países occidentales la polémica del hiyab, dado que en ellas se produce la confluencia Oriente/Occidente. No hay una investigación seria y global en el mundo islámico que estudie, por ejemplo, a través de una macroencuesta, las razones que llevan a las mujeres a velarse (Kerrou, 2003, p. 98). Una encuesta así nos permitiría, no solo conocer las razones que aportan las mismas protagonistas, sino que podríamos compararlas entre los diversos países y por edades, por su condición social, las explicaciones que dan las mujeres del mundo urbano y compararlas a las del mundo rural, etc. Existen, no obstante, algunas aproximaciones, como la de N. B. Weibel (2000), en su libro Par-delà le voile. Femmes d'islam en Europe. En él mostró en las mujeres musulmanas la complejidad de la presencia de esta religión en Europa; el libro recoge 84 entrevistas realizadas en Francia y Alemania entre 1989 a 1998 a mujeres de origen norteafricano y turco.

En mi caso, ante la dificultad de levantar una encuesta de ámbito regional o nacional, creo que elegir un colectivo concreto de estudio puede ayudarnos a comprender mejor todo este entramado, utilizando entrevistas en profundidad. La investigación a la que me refiero se centra en jóvenes universitarias. Primero, porque conforman la élite de sus comunidades de inmigradas (no en vano han llegado a alcanzar los estudios universitarios, superando un fracaso escolar muy agudizado entre sus compatriotas, siendo además mujeres). Segundo, porque se les supone un grado de formación académica y universitaria. Tercero, porque la inmensa mayoría de las jóvenes que nos están llegando a la universidad española o han nacido en España o migraron con sus padres cuando eran muy pequeñas (sin haber alcanzado los diez años), de manera que han sido educadas en una enseñanza occidental. Cuarto, se están educando en un ambiente universitario que es democrático, laico, crítico y de libertad. Quinto, se supone que serán futuras profesionales que superarán el estatus socioeconómico de sus padres. Por último, desde un punto de vista estratégico en el trabajo de campo, elegir la Universidad de Almería es muy comprensible, sobre todo porque la provincia, desde hace décadas, en sí es un laboratorio social, dado su alto número de población inmigrada, mayoritariamente musulmana, sin desmerecer el hecho de que las informantes son de fácil acceso, al ser un colectivo muy determinado, visible y abarcable y, a la sazón, donde ejerzo la docencia, algo que aporta autoridad moral.

La bibliografía al respecto es abundantísima: véanse, entre otros; Lamrabet, 2014; Bramón, 2006, 2013; Adelkhah, 1996; Amirian-Zein, 2009; Briones, 2009; De Botton, Taleb y Puigvert, 2004; Djavann, 2004; Maugham, 2007; Motilla (coord.) 2009; Murtada, 2010; Ramírez, 2011; Gómez, 2012, pp. 47-66; Torres y Pacheco, 2008; Benkheira, 1996. 
La primera impresión después de varias entrevistas es que las jóvenes musulmanas de hoy conocen muy bien que velarse es un compromiso que se adquiere de por vida, que les protege de las miradas lascivas de los hombres, que les hace mejores personas, que les priva de mostrar su belleza, siendo más castas y recatadas, para ellas y ante los varones. Sin embargo, escuchar las respuestas de las estudiantes no me impedía recordar a la escritora reformista iraní-francesa Chahdortt Djavann, quien, en su ensayo Abajo el velo (2004), escribe las tres primeras frases de manera lapidaria: "Durante diez años llevé el velo. Era el velo o la muerte. Y sé de qué hablo" (2004, p. 7). Más tarde aclararía: "El hiyab nunca ha sido inocente o inocuo. Siempre ha significado la sumisión de la mujer al hombre y la negación de los derechos legales a las mujeres en los países islámicos, por eso debería ser proscrito" 3 .

\section{EL HIYAB O VESTIMENTA ISLÁMICA EN EL CORÁN}

Muchos autores y autoras, especialmente musulmanes, se han dedicado a estudiar y desentrañar cómo aparece la cuestión del vestido islámico en los textos originales del islam: Corán, Sunna y Fiqh; se trata, sin duda, de un laberinto religioso, moral, político y costumbrista. Por citar algunos, véanse A. Lamrabet (2014); D. Bramón (2006); E. Pascual (2015) o el capítulo quinto de la obra de F. Mernissi, El harén político. El Profeta y las mujeres (1999). En una anterior publicación (Checa, 2019, p. 11ss) llevé a cabo un resumen de las fuentes del derecho islámico y el tratamiento que realizan del hiyab. Sabemos que es difícil entrar en una discusión teológica exhaustiva sobre este tema (máxime cuando se trata de traducciones desde el árabe clásico, que pocas personas dominan, y no olvidando que en árabe hiyab significa tanto pudor como protección, esconder, ocultar a la vista o cortina $)^{4}$, pero conviene saber, al menos, lo siguiente. De manera sintética:

Del total de 6.236 aleyas (versículos) de las que el Corán se compone, en sus 124 suras (capítulos), solo 17 se relacionan con el hiyab. Y de estas, en solo 3 ocasiones Muhammad 5 (Corán 24: 31; 33: 53, 59) ${ }^{6}$ se refiere a lo que podemos llamar hiyab-e zaher (cortina o vestimenta), pero nunca sin precisar la forma que esta tiene o debe llevar. Aun así, Bramón (2006, p. 121) dice que en estas tres ocasiones no se refiere a hiyab, sino que en el árabe clásico cita literalmente la jalabihinna, que corresponde a la prenda de vestir externa que en aquella época llevaban las mujeres para distinguirse de las esclavas.

Incluso A. Lamrabet (2014, p. 42) asegura que en realidad son solo dos aleyas (24: 31; 33: 59). También aparece con la acepción de Libass atquwa: "vestido de la piedad" o de la

http://www2.memri.org/espanol/escritora-reformista-irani-francesa-chahdortt-djavann-el-hijab-es-un-arma-politica-unaforma-de-abuso-sexual-y-deberia-ser-proscrito/3050.

$4 \quad$ Cuando en el Corán se refiere a la vestimenta -o de lo que parece tener relación con el cuerpo- utiliza solo los siguientes conceptos: ghad y bassar, hafd el faraj, hiyab, khimar, jilbab y libass atquwa.

$5 \quad$ Se trata de Muhammad ibn Abdel.lah. Era descendiente del profeta Abraham a través de su primogénito el profeta Ismael, padre de los árabes. Nació en Meca entre el 12 y el 17 del mes de rabbi l-awal del año 570 de la era cristiana. Su abuelo, Abd al-Muttalib, le puso un nombre que jamás otro ser humano había tenido anteriormente. Le llamó Muhammad. Cuando fue preguntado por la razón de un nombre tan poco usual, respondió: "Quiero que sea alabado tanto en los cielos como en la Tierra". Se relata que Muhammad nació con la circuncisión hecha y sin cordón umbilical y que en el momento de nacer dijo: "Dios es más grande. A Él pertenece la alabanza. Glorificado sea mañana y tarde".

$6 \quad$ La sura 24 se titula An-Nur (de La Luz), la sura 33 Al-Ahzáh (o La Coalición). 
“interioridad”, tanto para las mujeres como para los hombres (Corán 7, p. 26): “iHijos de Adán! Hemos hecho bajar para vosotros una vestidura para cubrir vuestra desnudez y para ornato. Pero la vestidura de la piedad (taqwa), esa es mejor". Dice Lamrabet (2014, p. 42) que aquí la importancia se da a la interioridad o taqwa y no a las apariencias.

Primero, en el Corán el concepto hiyab o velo tiene que ver con "cortina" o "separación" en las seis siguientes citas: Corán 7: 46, 17: 45, 19: 16-17, 38: 32, 41: 5, 42: 51 Por otro lado, el velo también se refiere expresamente a las mujeres de Muhammad (Corán, 33: 32, 33, 33: 53). El concepto utilizado es hiyab, no como vestido, sino como cortina o separación. Y, en tercer lugar, algunas aleyas se refieren directamente al cubrimiento del cuerpo de las mujeres, al menos en las tres ya citadas (Corán 24: 30, 31, 33: 59). "Y di a las creyentes que recaten sus miradas y protejan sus partes privadas y no muestren sus encantos, excepto lo que está a simple vista. Que cubran sus pechos con el velo [khimar] y que no muestren sus encantos excepto a sus esposos, sus padres..." (24: 31). "¡Oh, Profeta! Di a tus esposas y a tus hijas y a las mujeres de los creyentes que se cubran todo el cuerpo con sus túnicas [jilbab]. Eso es mejor para que sean reconocidas y no sean molestadas" (33: 59). "Y las mujeres mayores que ya no cuentan con casarse, no cometen pecado si relajan su vestimenta (...). Pero es mejor para ellas que se recaten" (24: 60).

Los conceptos utilizados en el Corán son: ghad y bassar y hafd el faraj. Se refiere al recato. Cuando habla de khimar (en 24: 31) sí se refiere a pañuelo o velo. Al hablar de jilbab se refiere al manto largo y amplio propio de la época en la cultura arábiga.

Es, pues, fácil apreciar que en el Corán hiyab no se corresponde a un concepto relacionado con la apariencia física o, como está entendido hoy, con el pañuelo o el llamado vestido islámico; sobre todo significa "separación" o "cortina". Ciertamente se usó una vez en el caso de las esposas de Muhammad, donde se pedía a los creyentes que hablaran con ellas detrás de un hiyab -cortina o separación- y eso se debe al contexto de la época y por respeto a la privacidad de Muhammad y de sus mujeres. Así es, Corán 33: 53, "Creyentes! No entréis en las habitaciones de Muhammad a menos que se os autorice a ello para una comida. No entréis hasta que sea hora. Cuando se os llame, entrad y, cuando hayáis comido, retiraos sin poneros a hablar como si fuerais de la familia. Esto molestaría al Profeta y, por vosotros, le daría vergüenza. (...). Cuando les pidáis un objeto hacedlo desde detrás de una cortina. Es más noble para vosotros y para ellas". Se trata, incluso dentro de la casa de Muhammad, de una separación entre el espacio público -donde los demás entran y comen, conversan o consultan aspectos de su vida y forma de actuar- y el privado, reservado a los aposentos de sus esposas.

Para Bramón (2006, p. 121) y Lamrabet (2014) en Corán 33: 59 el término del árabe clásico que figura por manto es el de jalabihinna, o jilbab:

"y que no creo que se haya de entender como la obligación de las mujeres vayan totalmente tapadas por la calle, sobre todo si se recuerda que los fragmentos citados permiten imaginar que con el clima de Arabia sus habitantes estaban en casa con poca ropa o incluso sin ella (Lamrabet, 2014, p. 41).

Este versículo, continúa Lamrabet, "fue revelado en un contexto particular donde las primeras creyentes que iban por la noche a la mezquita eran asaltadas por los hombres". La mayoría de las interpretaciones afirman que fue una medida para protegerlas y para que fueran reconocidas como creyentes. 
En Corán 24: 31 el pañuelo o velo se traduce desde khimar: "Y di a las creyentes que bajen la vista con recato, que sean castas y no muestren más adorno que los que están a la vista, que cubran su escote con el velo (khimar) y no exhiban sus adornos (zinatiuhouna) sino a sus esposos, a sus padres, a sus suegros, a sus propios hijos". Aquí se pide a las creyentes que se cubran el pecho y el cuello (el jayb) con los bordes del pañuelo" (yadribna bi khumurihina ala juyubihina). Y también que no hagan ostentación de su "belleza" (zina) a los hombres que no sean de su familia. No se detalla más cómo ha de ser la forma de mostrarse ni a qué se refiere esa belleza. Aquí se puede interpretar de diferentes maneras, porque no se ve exactamente unas normas descriptivas fijas, pero la mayoría de los ulemas lo han interpretado como una prescripción que impone que lo único que debe verse es el rostro, las manos y los pies, basándose en algunos hadizes.

En resumen: la revelación de Alá a su Mensajero no es que las mujeres cubrieran su cuerpo cuando salieran a la calle, sino que fueran recatadas. Y que a las mujeres de Muhammad se las respetara y miraran desde una separación o detrás de una cortina.

\section{LA ENTREVISTA SOBRE EL HIYAB. RESULTADOS}

Los resultados que presento a continuación se basan en una serie de 30 entrevistas en profundidad realizadas a estudiantes musulmanas, la mayoría (24) matriculadas en la Universidad de Almería. Para esta presentación no tomo en cuenta la etnografía de los 4 grupos de discusión también llevados a cabo, ni las entrevistas a los jóvenes musulmanes varones.

Todas las entrevistas han sido llevadas a cabo por el investigador, excepto dos, que fueron autoadministradas. Los lugares han sido en domicilios de las jóvenes (El Ejido, las Norias de Daza, Roquetas de Mar, La Mojonera, etc.) y en mi despacho de la Universidad. En algunas han estado presentes en diversos momentos el padre, madre o hermano/a de la entrevistada, animándolos a que participaran, si lo deseaban. El sistema de búsqueda de informantes no ha sido complicado, dado que es muy fácil detectar a una estudiante que lleve hiyab. El índice de aceptación para realizar la entrevista ha sido prácticamente del 100\% (solo dos jóvenes han declinado la invitación). Diría, incluso, que llegaban con orgullo y se prestaban con alegría y agradecimiento, manifestando su felicidad porque alguien se había preocupado del tema. El efecto de bola de nieve ha funcionado a la perfección, pues entre ellas se lo han ido comunicando, incluso acompañando al despacho a otras compatriotas.

Las entrevistadas abarcan la mayoría de los grados que hay en el UAL: Magisterio, Enfermería, Turismo, Historia, Psicología, Matemáticas, Biotecnología... también algún máster y una doctora en Ciencias Económicas. Seis no son universitarias, sí estudiantes de ESO (3), segundo de bachiller (1) o un módulo de formación (2). El elemento más criticable a la investigación es que casi la totalidad de las estudiantes son marroquíes o de origen marroquí (excepto dos extranjeras en situación de estudiante erasmus). En realidad, responde al perfil de estudiante musulmana matriculada en la UAL. Todas se han hecho en español, porque la totalidad de las entrevistadas hablan este idioma a la perfección. La primera tuvo lugar el 10 de agosto de 2017 y la última el 18 de julio de 2018.

La entrevista está dividida en ocho apartados: (i) datos personales, (ii) aspectos personales y formales de sobre el hiyab y sus razones para ponérselo, (iii) relación de sus 
familiares más cercanos con el hiyab, (iv) respuestas/reacciones de la familia, vecinos y conocidos ante el hecho de ir veladas, o no, (v) conocimiento religioso de la prescripción de ponerse el hiyab, (vi) llevar hiyab y su relación con la integración social en España, (vii) el hiyab en la UAL, (viii) ante qué razones o situaciones ellas llegarían a quitarse -o no- el hiyab.

\subsection{DATOS SOCIODEMOGRÁFICOS}

Todas las entrevistadas, excepto dos señoras, una casada y otra divorciada, están solteras. De una edad que oscila entre los 18 y 44 años. Las no universitarias tienen entre 15 y 17 años.

Han nacido en España 5, el resto, 23, llegaron a España (la mayoría directamente a la provincia de Almería) cuando eran muy pequeñas. Las dos restantes son estudiantes erasmus (una inglesa y otra belga). A saber, 3 tenían menos de un año, 8 entre dos y tres años. Entre cuatro y cinco años, 4. Jóvenes que llegaron entre seis y diez años, otros 4. Con más de diez años, 4, aunque ninguna con más de 15 años. Son lo que A. Portes llamaría de generación 1.5: nacidos en el extranjero, pero llegados a España en la infancia, antes de los 12 años. Las 8 jóvenes que hay entre las nacidas ya en Almería o que llegaron con menos de dos años, aunque las estadísticas les denominen inmigrantes de segunda generación, nada de eso es correcto, pues cómo llamar emigrantes a quienes ni siquiera han viajado.

En consecuencia, la totalidad de las entrevistadas (excepto las dos erasmus) han estudiado la ESO y el Bachiller en centros almerienses. En el momento de ser entrevistadas hay estudiantes de los cuatro cursos de grado, en primero, 7; en segundo, 5; en tercero, 4; en cuarto, 3.2 son de máster, 2 están matriculadas en algún programa de doctorado y una ya es doctora.

\subsection{EL HIYAB ENTRE LAS ESTUDIANTES DE LA UAL}

Nuestra intención es conocer el uso del hiyab entre las estudiantes musulmanas que están matriculadas en la UAL, para ello no solo hemos entrevistado a quienes van ataviadas con el hiyab, también a quienes, siendo musulmanas, no van veladas.

16 personas de la muestra no llevan pañuelo, es decir, prácticamente visten a la europea; si bien es cierto que alguna de ellas nunca se pone pantalones ni ropa ajustada, disimulando u ocultando sus volúmenes (pechos y caderas).

El resto, 14, sí van veladas en su vida normal. Todas ellas llevan hiyab, excepto 2 muchachas que visten jilbab (una de manera regular y otra ocasionalmente). De quienes portan hiyab, 8 solo lo lleva como pañuelo que les tapa el pelo y orejas, cuello y pechos; para el resto del cuerpo van ataviadas con pantalones o alguna ropa ancha. Aunque 6 visten completamente al modo islámico, es decir, como una indumentaria que deja a la vista solo las manos y el óvalo de la cara. Alguna confiesa que, de vez en cuando, le gusta vestirse "como si viviera en un pueblo de Marruecos" (es decir, chilaba y velo).

No he encontrado ninguna muchacha que vista chador; mucho menos niqad o burka. Tampoco ellas conocen a nadie que en Almería lo porte. En realidad, en los casi 30 años que llevo residiendo y visitando ciudades en la provincia únicamente he encontrado a tres mujeres mayores que visten niqab: una en Roquetas de Mar (verano de 2018) y dos en Almería (2017 y primeros de 2019). Sin embargo, al hacer referencia a estas circunstancias, 
algunas entrevistadas las han considerado como "mujeres valientes". Tres de nuestras entrevistadas así lo confirmaron: "Me gustaría tener esa fortaleza. Seguro que lo haré cuando sea mayor", aseguró Saliha (o se casen).

La edad con la que las estudiantes veladas se pusieron el hiyab por primera vez oscila entre los 9 años, el caso de Meryam ("por pura rebeldía"), hasta los 16 años (con 9 años: 1; 10 años: 1; 11 años: 1; 12 años: 1; 13 años: 2; 14 años: 4; 15 años: 1; 16 años: 3). De sus palabras se deduce que no fueron decisiones transitorias, pues ninguna se lo ha quitado, al menos de manera voluntaria. Conocen a compañeras, amigas o vecinas que sí se lo han llegado a quitar (aunque "no es una situación muy extendida: seguramente, no se lo habían puesto muy convencidas de lo que hacían"). Tres jóvenes que hoy no llevan hiyab sí fueron veladas algún tiempo. Cinco entrevistadas aseguran conocer -dos refieren a sus propias madres- a mujeres que para ir al trabajo se quitan el hiyab, volviendo a ponérselo a la salida.

A un lector no musulmán pudiera parecerle que es muy jóvenes una chica de 9 u 11 años para velarse con un hiyab para toda su vida, en cambio todas las que hoy lo llevan y han respondido a la entrevista, aseguran que eran conscientes de lo que hacían. Incluso más de una llegó a afirmar que no se lo pusieron antes porque "mi padre me lo impidió".

Las entrevistadas saben que llevar el hiyab no es por una decisión que obedezca a una moda, ni con la intención de probar para ver cómo se sienten, sino que, lejos de ser pasajero, es una situación que debe perdurar en el tiempo, ya que llegan a esa decisión por una cuestión religiosa, convencidas de que es una prescripción coránica y que de esa forma se sienten esclavas (o sumisas) de Alá, como dicta el Corán.

\subsection{ANTECEDENTES FAMILIARES}

Los antecedentes familiares más allegados de las estudiantes musulmanas son evidentes e idénticos: en todos los casos las madres de las entrevistadas, excepto dos, llevan velo. Muchas de ellas se lo habían puesto incluso antes de casarse o una vez que contrajeron matrimonio, cuando aún vivían en su país de origen (la gran mayoría en Marruecos). La afirmación de si fue por decisión propia o influidas por sus maridos no queda clara, dado que la respuesta más común de sus hijas es: "no lo sé". Del resto de afirmaciones se deduce que lo hicieron movidas tanto por sentimientos religiosos como por cuestiones culturales: "en mi país es una costumbre", ahondando en ello las que proceden del mundo rural, debido a que el control social es muy fuerte. Así se entiende que aquellas dos jóvenes digan de sus madres: "pero cuando vuelven a su pueblo en Marruecos algunas veces se lo ponen".

De las 28 entrevistadas que viven en la provincia de Almería -recordemos que dos eran estudiantes erasmus- 10 aseguran que en su hogar además hay al menos una hermana -mayor o menor- que también va velada.

\subsection{LAS PRESIONES FAMILIARES Y DEL ENTORNO}

¿Tienen presión estas jóvenes para ponerse un hiyab? La decisión de velarse con el hiyab, como una disposición voluntaria, propia y en libertad, es el denominador común en las respuestas: "créeme, profesor, es una decisión completamente mía" (Aicha). La totalidad ha respondido que, directamente, nadie le ha obligado a velarse (aunque conocen a algunas amigas que sí). Pero sí han sentido sobre sí mismas ciertas influencias a través de 
comentarios de su madre, de las vecinas musulmanas, incluso de sus hermanas y hermanos mayores, principalmente los varones, como un ejercicio de protección social. Ninguna destaca a su padre como un ser influyente para que se velen, más bien al contrario: "mi padre me dice que me lo quite, para que no tenga discriminación" (Zineb). "A mí mi padre me obligó a que me quitara el jilbab cuando tenía 13 años, porque acababan de pasar lo de los trenes de Atocha y tenía miedo a que nos tomaran por yihadistas", me aseguraba Imane. Isham, quien en la actualidad no lleva velo, aseguró: "mi hermano mayor pasa de mí sobre si me pongo el hiyab o no, pero mi hermano el segundo, que es muy conservador, no paraba de decirme que me pusiera el pañuelo. Me dejó tranquila cuando vio que no le hacía caso".

Como se ve, el caso de quienes no llevan el hiyab es diferente. No tanto en su relación con sus padres, sino con las vecinas, así acabo de apuntarlo. De las 16 estudiantes que no llevan pañuelo, todas mantienen, de una u otra manera, que su ambiente le reclama que se velen. Hay que tener presente que el calificativo que les ponen es "vas desnuda". "A mi madre mi vecina no para de decirle que no me deje venir a la universidad desnuda", asegura Fatine.

\subsection{SOBRE EL CONOCIMIENTO DEL HIYAB EN LOS LIBROS RELIGIOSOS}

De las 30 estudiantes entrevistadas, excepto Islam, ninguna ha sido capaz de recitar la aleya donde se habla del hiyab. En puridad, su desconocimiento es total. Muy pocas han logrado decir que aparece en la sura de "La luz"; pero no saben que es la sura 24. Algunas confunden la aleya con algún hadiz (dicho del Mensajero) que hace mención al hiyab como vestimenta de la mujer. Entienden que se refería a las mujeres de Muhammad. Saben que hay aleyas que refieren el hiyab y que en algunos casos se refiere a "separación" o cortina, pero no he encontrado a ninguna que lo recitara, ni que le diera excesiva importancia a su capacidad para saberlo y su relación directa con que vaya o no velada. Solo algunas entrevistadas han sabido que de las 17 aleyas en las que se habla de hiyab, únicamente 3 hacen mención al vestido de la mujer (alguna estudiante menciona que son dos).

Lo que sí conocen es que el Corán habla de bajar la mirada y que el recato advierte tanto al hombre como a la mujer. Pero, como decía Hasnae que siempre le advierte su madre: "Tú ve tapada que si te pasa algo, la culpa será tuya por ir como vas". Reconocen que el varón siempre sale indemne de estas situaciones de acoso o incordio. Hay una aceptación generalizada de que los marroquíes varones son muy fogosos, irrespetuosos y mal educados.

\subsection{EL HIYAB COMO ELEMENTO DE DISCRIMINACIÓN}

Este bloque de preguntas pretende descubrir si las musulmanas entienden que llevar hiyab es -o puede ser- un elemento de discriminación para la mujer que lo porta. Las respuestas iban enfocadas hacia la integración social, la posibilidad de encontrar trabajo, tener amigos/ as españoles y en otras situaciones de la vida diaria, como ir al gimnasio o estar en la playa. La inmensa mayoría cree que el velo no debería ser un elemento de discriminación; de hecho, aseguran que la sociedad española cada vez está más acostumbrada a ver por la calle mujeres con el hiyab. Sin embargo, asumen que en este país, como en otros europeos, el hiyab puede llegar a ocasionar situaciones de exclusión. Sobre todo para encontrar un puesto de trabajo, donde destacan dos situaciones: los que llevar el pañuelo puede ser 
objeto de peligro en su desempeño laboral, porque se enrede en alguna máquina -ponen el ejemplo de las cadenas de clasificación del género hortofrutícola, por ello solo se permite un gorro de tela y una bata, cuello y brazos libres- segundo, cuando la mujer debe estar de cara al público, como el empleo de la medicina, la docencia o una oficina de atención ciudadana. Son la experiencia de sus madres, hermanas o vecinas las que avalan esta percepción.

Parece evidente que sus madres, dada la formación que trae la mayoría de sus países de origen, en sus aspiraciones no está trabajar en puestos cualificados, pero sí que lo podrá ser en pocos años para ellas, que estarán formadas para realizarlos, igual que una chica española de su edad. A la pregunta de si se quitarían el hiyab para acceder a un puesto de trabajo (aunque en este momento no lo lleven), hay división de opiniones: 12 de las 30 aseguran que no: "nuestras vidas estén en manos de Alá. Él buscaría otro remedio para nosotras", asegura con firmeza Saliha.

En sus respuestas se traduce perplejidad cuando algunas jóvenes aseguran que amigas y amigos suyos se alejaron cuando aparecieron con el hiyab. Aunque no debe entenderse tanto como un desprecio, cuanto que han sido ellas las que no frecuentan los lugares de ocio donde la juventud se reúne, como bares, los pubs, la playa, o los parques para hacer botellón. Ahí no vamos a encontrar una chica con hiyab. Ello significa que su círculo de relaciones se reduce a las chicas marroquíes o musulmanas, lleven o no pañuelo. Se ven en casa de alguna, en un parque sentadas, para pasear, o van a tomar un café a un bar. "No se trata de que nos desprecien o despreciemos a nuestros amigos y amigas de antes, es que ellos y ellas frecuentan unos sitios donde nosotros no vamos", decía Fátima con contundencia.

Respecto al efecto que supone llevar hiyab para acudir a determinados lugares, públicos o privados, como puede ser la playa o un gimnasio, las entrevistadas sí aprecian un hándicap, sobre todo en la playa. Fatine conoce a alguna amiga suya que va al gimnasio con el hiyab. Naima asegura que le gusta mucho la playa y tomar el sol, pero que no puede ir cuando está llena de gente, para no despertar las miradas de mofa. En cambio, Aicha asegura que ella va a la playa sin problemas, incluso se mete en el agua tal como va. Su anécdota es llamativa: "una vez una amiga mía y yo fuimos a la playa. Como no había nadie alrededor me quité el hiyab -porque mi amiga no lleva- y nos bañamos sin pudor. La muy tonta, cuando estaba despistada me gastó la broma con eso ¡que viene un hombre! Y me iba a morir, jajaja".

\subsection{EL HIYAB EN LA UAL}

La pregunta respecto al uso del hiyab en la Universidad de Almería es clara: “¿Crees que en la UAL se discrimina a las estudiantes que llevan hiyab?" Ninguna entrevistada ha contestado afirmativamente con rotundidad. Ni por parte del profesorado en clase, ni del PAS, en las fotocopiadoras, en las cafeterías, la biblioteca o andando por los pasillos. Solo una estudiante del grado de Química, que va velada, aseguró que sentía cómo una profesora no la miraba como a las demás; incluso llegó a afirmar que un profesor, cuando levanta la mano para preguntar algo, la ignora y no le da la palabra. ¿Por ser musulmana?, le pregunté. "No lo sé con certeza, pero a mí me parece que sí".

Puede tratarse de cierta incomodidad al saberse miradas/observadas, como diferentes. Otra joven asegura que una limpiadora oyó decirle algo en voz baja, "yo creo que era 
despreciativo", pero no aclara qué. Ninguna afirma haberse sentido ofendida ni directamente atacada, ni conocen a amigas estudiantes que sí les haya ocurrido.

\subsection{EL HIYAB COMO BARRERA}

A la pregunta de si el hiyab estuviera prohibido para entrar en clase, cómo actuarían, las respuestas han sido casi unánimes: no se lo quitarían. En realidad, como entrevistador, al formular esta pregunta observaba en sus caras la incredulidad, que viene a significar: "ipor qué tengo que quitarme una prenda de vestir para entrar a clase!" Les parece imposible que esto llegara a suceder. Pero sus respuestas, en el caso hipotético de que se diera, dentro de la variedad, la mayoría afirma que prefieren no entrar en clase a desvelarse. Estudiantes como Imane aseguran que irían a protestar al Defensor Universitario, o el Decano; otras, como Isham, mantienen que entrarían, sí o sí, porque han pagado una matrícula donde no ponía que debían ir desveladas para asistir a clase. Saliha mantiene que abandonaría la carrera, antes de desvelarse. Otras creen que lo mejor sería cambiarse de universidad.

Donde en las estudiantes se aprecian más dudas y menor firmeza en sus respuestas o elección de sus actuaciones es ante el caso de que les ofrecieran un puesto de trabajo -incluso correspondiente para el que se han formado, como psicóloga o enfermera- y que les fuera negado por el hecho de llevar el hiyab. Aseguran que, si ese puesto no se lo dan por llevar el hiyab, buscarían otro idéntico -o similar- en ciudades diferentes, o cogerían un puesto de trabajo distinto. Saben que Alá las protege y no por un puesto de trabajo van a dejar de ser sumisas a Él.

Pero algunas entrevistadas, como Yasmine, creen que tendrían que valorar las circunstancias personales y familiares del momento. Responder desde la juventud y sin ninguna persona que dependa de ellas es más fácil que si eres cabeza de familia y la alimentación de tus hijos dependen de su sueldo laboral: en ese caso se lo quitarían sin dudar. Y a la salida del trabajo volverían a colocarse el hiyab.

Donde no tienen dudas es a la hora de responder a las dos últimas preguntas, que tienen que ver con las relaciones de pareja: todas aseguraron que ni se quitarían ni se pondrían el hiyab porque su prometido se lo pidiese. Es un acto de estricta libertad personal. La más contundente fue Fatine, al modo español: "si eso me lo pide un chico... ¡le doy dos hostias, ¡quién se ha creído que es él y que soy yo!”

Caso diferente es si ya estuvieran casados. Ahí la influencia para ponérselo es diferente, también al verse como esposa y madre, el ejemplo para sus hijos es muy importante, aseguraba.

\section{DISCUSIÓN}

Las entrevistas nos dejan algunos datos para el debate y la reflexión. Primera: Desde el mundo occidental tenemos un gran desconocimiento de la cultura islámica, no solo de sus aspectos religiosos (el Corán, la Sunna o la Sarhia), también de su cultura y desarrollo actual, de su situación económica y política. Llama la atención el alejamiento social e imaginario que desde España se dispensa a Marruecos, un país tan cercano y con tantos lazos históricos recientes (no en vano su parte norteña/rifeña fue protectorado español hasta 1956), que, por lo demás, no deja de ser la mayor colonia de inmigrantes en España, junto 
con la rumana. En el territorio español, del total de 47.007.367 habitantes, hay residiendo 5.025.264 extranjeros (10,7\% sobre el total), con datos oficiales del INE a primero de enero de 2019. De ellos, 812.412 son marroquíes, que representa el 16,1\% sobre el total de extranjeros y el 1,7\% sobre el conjunto de la población que reside en España. En la Comunidad Autónoma de Andalucía, del total de población, 8.410.002, son extranjeros $653.146(7,7 \%$ sobre el total) y 154.181 marroquíes $(1,8 \%$ sobre el total de la población, pero $23,6 \%$ sobre el total de los extranjeros). En la provincia de Almería (715.993 total de habitantes y 145.181 extranjeros), la colonia marroquí son 57.650 personas, que representa el $8 \%$ sobre el total y nada menos que el $39,7 \%$ sobre el conjunto de extranjeros que residen en la provincia.

Es este un desconocimiento que nos debería preocupar, dado que un buen número de personas pertenecen a la llamada segunda generación, pero muchas de ellas, como se puede comprobar en las entrevistas, o son nacidas ya en Almería, o llegaron siendo bebés o en la tierna infancia. Por ende, han sido educados en nuestro sistema educativo, socializados en nuestras calles y plazas, hoy llegan a la universidad y no hemos logrado, entre ambos grupos, que se sientan ciudadanos de esta tierra.

Segunda: nuestro desconocimiento nos permite alimentar y mantener una serie de prejuicios que nos lastran nuestra capacidad de integración. También el colectivo musulmán juega su papel de presentar un Occidente poco atractivo para los intereses de su religión y cultura. Los últimos acontecimientos del terrorismo universal yihadista son elocuentes y no favorecen para nada las relaciones normalizadas entre ambas partes de la población, recelosas unas de otras cada vez más. Ellos son, para nosotros, fundamentalistas y potenciales terroristas; nosotros somos, para ellos, represores y aniquiladores del islam. La falta de entendimiento, de diálogo y confianza es una brecha cada vez amplia. La educación, en su sentido más amplio, como ámbito social y de formación, debe jugar un papel irrenunciable en favor de la paz y el conocimiento mutuo. La integración social es imposible desde el recelo. Este clima lo están percibiendo de manera muy clara los grupos de musulmanes, retraídos hacia sus propias pautas culturales y religiosas. "Nosotras no somos un problema para la integración, si nos dejan hacerlo como es debido y en paz", reclamaba Islam.

Tercera: la juventud musulmana está dentro del sistema socioeconómico español. Por fortuna, ya está cada vez más superando el fracaso escolar de los primeros años de asentamiento. Los jóvenes musulmanes también están presentes en el ámbito universitario, con una presencia cada vez mayor de mujeres, luego en los próximos años se verán competir por los mismos puestos de trabajo que los nacionales, sabiendo que han salido de las mismas aulas. Y en unos años no podremos -no deberemos- hacer una distinción entre "nuestros jóvenes" y "ellos", porque serán -ya lo son- todos ciudadanos españoles, independientemente del origen de sus padres.

Cuarta: las muchachas universitarias de origen marroquí no parecen mujeres sumisas, que actúen al dictado de sus padres y hermanos. No significa esto negar la evidente influencia que en todo ser humano tiene la cultura $-\mathrm{y}$ la familia- en la que se educa, pero de las entrevistas no se deduce que estas universitarias no sepan cuáles son sus prioridades en la vida y den la apariencia de chicas ancladas al pasado, a pesar de vestir con hiyab. Son occidentales, se sienten occidentales y saben que van a estar preparadas para afrontar el futuro, lo que no les impide ser musulmanas y querer ejercer como tales. La cuestión está en saber si podrán hacerlo como "inmigrantes" permanentes o como ciudadanas españolas. 
Quinta: el hiyab es una prenda con la que los occidentales tendremos que acostumbrarnos a convivir; o lo que es igual: tratar con mujeres que van libremente ataviadas con el jilbab o el hiyab, cotidianamente, en sus puestos de trabajo y en los espacios públicos. O que irán a bañarse en el mar - $\mathrm{O}$ una piscina pública- con un burkini, con toda naturalidad.

Sexta: las mujeres musulmanas saben perfectamente que el Corán prescribe el hiyab en las mujeres, independientemente del tipo de prenda que se lleve (hiyab, jilbab, chador, incluso el niqab). En muchos lugares deviene de imposiciones legales y, en cualquier caso, es una prescripción social, una pauta cultural arraigada en el derecho consuetudinario. En consecuencia, en un mundo patriarcal y machista, la mujer tiene un espacio muy reducido de actuación y cualquier gesto que salga de la norma es visto como un gesto de desobediencia a Alá, por tanto, susceptible de ser censurado y castigado. Así piensan algunas: "El hiyab hay que llevarlo, sí o sî”, dice Saliha con pleno convencimiento. Incluso las estudiantes que no lo llevan son conscientes de que algún día se lo pondrán, seguramente al casarse, sin necesidad de que su marido se lo pida, como responsabilidad propia. Alguna también ha asegurado en la entrevista que jamás se lo pondrán, sin necesidad de sentirse musulmanas de inferior categoría.

Séptima: como puede apreciarse, la cuestión del hiyab es de muy difícil tratamiento, por ello ha de ser abordada desde diferentes ángulos, algunos espinosos. Pero, en ningún caso puede obviarse la libertad de las mujeres. Las musulmanas, aunque procedan de países dictatoriales, no pueden ser consideradas como personas en una permanente minoría de edad, solo por el hecho de usar hiyab. Además, en el islam inmigrado las mujeres sienten una mayor libertad (si bien no faltan asociaciones y partidos que las presionan e incitan a que sigan el ejemplo de esas mujeres que, veladas, muestran su disconformidad con el machismo que sufren) y así lo reivindican. Porque, para ellas, además de un precepto religioso, en los países occidentales el hiyab viene siendo interpretado como un elemento de identidad cultural, que les recuerda a sus orígenes y da un sentido de pertenencia a la umma (comunidad universal de creyentes).

Sin embargo, octava y última, conviene tener presente el miedo creciente que en occidente ha devenido del auge de los movimientos fundamentalistas islamistas, en una reislamización sin precedentes y, como reacción, el crecimiento de los partidos xenófobos y antiinmigración que han llevado a los gobiernos centroeuropeos a legislar para prohibir la vestimenta islámica en lugares públicos. Estas prohibiciones, a su vez, reactivan y retroalimentan ideas islamistas extremistas e incitan a las mujeres inmigradas a la desobediencia, siendo el burka, el nikab o el chador prendas que cada vez más visibilizadas en las calles de las ciudades europeas. Para las organizaciones islamistas es una acción política de conquista de espacios públicos y hacer visible el avance del islam en el mundo. Para las mujeres -muchas de ellas pertenecen a la segunda o tercera generación de inmigrados- es un gesto de reivindicación del derecho de culto y de creencia religiosa. Así, aunque parezca paradójico, el papel legislador occidental contra ciertas costumbres islámicas deja a las mujeres en una situación de debilidad social. Es muy posible que con estas leyes tan restrictivas se esté condenando a buena parte de la población a la exclusión y el ocultamiento.

En consecuencia, como escribí hace unos meses (Checa, 2019, p. 30):

las mujeres occidentales no pueden interactuar con las musulmanas si estas consideran que han de ser tutoradas en sus reivindicaciones o consideradas como personas en 
minoría de edad. Las mujeres occidentales no pueden liberar a las mujeres musulmanas del yugo del hiyab, de un lado, porque estas no consideran que tengan que liberarse de él, de otro, porque la libertad del colectivo de mujeres musulmanas quizá no pase por arrojar el velo al suelo para liberarse de la esclavitud machista. Sino, más bien, antes que exigir a sus vecinas musulmanas que se desvelen, creo más imprescindible que, primero, las mujeres occidentales les ayuden a acceder a puestos de trabajo dignos, para salir de la reclusión y asilamiento de sus casas y sus barrios; que, segundo, aprendan correctamente el idioma, posibilitando una mejor inserción y libertad para ir al médico, al banco o charlar con las vecinas, sin necesidad de un intérprete; que esas mujeres, tercero, tengan un acceso a la educación de manera más prolongada, lo que redundaría en su formación y aumentaría las posibilidades de encontrar un trabajo diferente al del servicio doméstico o la limpieza en la cocina de un restaurante.

Decía Nawal al Saadawi que el único velo que había que hacer desaparecer es el velo de la mente. Cuando un periodista le preguntó a F. Mernissi por su hiyab, esa socióloga marroquí que en Marruecos se quitaba el pañuelo y se lo ponía en París, ella respondió: "En lugar de preocuparse por lo que tengo sobre la cabeza, ¿por qué no se interesa por lo que tengo dentro de ella?" (citado en Torres, 2014, p. 171).

\section{REFERENCIAS BIBLIOGRÁFICAS}

Abu Amina, E. (2017). La diferencia entre Sharia, el Fiqh y la Ley islámica. Muslim New. En línea: http://www.new-muslims.info/es/forma-de-vida/la-sociedad/la-diferencia-entre-la-sharia-elfiqh-y-la-ley-islamica/.

Adelkhah, F. (1996). "Vestidos de mujer". La revolución bajo el velo. Mujer iraní y régimen islamista. Barcelona: Bellaterra, 217-236.

Adlbi Sibai, S. (2014). El 'hiyab' en la obra de Fátima Mernissi o la paradoja del silenciamiento. Hacia un pensamiento islámico decolonial. Tabula Rasa, (21), 47-76.

Aláez Corral, B. (2011). Reflexiones jurídico-constitucionales sobre la prohibición del velo islámico integral en Europa. UNED. Teoría y Realidad Constitucional, (28), 483-520.

Aliyah, Z. (2016). Grandes mujeres olvidadas en la historia del islam. En línea: https://funci.org/ grandes-mujeres-olvidadas-en-la-historia-del-islam/.

Amirian, N. y Zein, M. (2009). El islam sin velo: un acercamiento serio y riguroso a la cara más desconocida del mundo islámico. Barcelona: Bronce.

Amorós, C. (2009). Notas para el debate acerca del uso del velo islámico. En Vetas de Ilustración. Reflexiones sobre feminismo e Islam. Barcelona: Cátedra, 79-90.

Andújar, N. (2005). El velo, ¿principio fundamental del islam? En línea: www.webislam.com/ articulos/2749-el_velo_principio_fundamental_del_islam.html.

(2007). Pañuelo sí, pañuelo no, esa no es la cuestión. En línea:www.webislam.com/ articulos/32460-panuelo_si_panuelo_no_esa_no_es_la_cuestion.html.

Aya, A. (2010). El islam no es lo que crees. Barcelona, Kairós.

Ben Jelloun, T. (2015). El islam que da miedo. Madrid: Alianza Editorial.

Benkheira, M. (1996). Le visage de la femme. Entre la Sharî'a et la coutume. Anthropologie et sociètès, 20(2), 15-36.

Bramón, D. (2006). La pretendida obligatoriedad del velo islámico. En Ser mujer y musulmana. Barcelona: Bellaterra, 118-131.

. (2013). Los fundamentos del poder en el islam. En O. Orozco y G. Alonso (eds.), El Islam 
y los musulmanes hoy. Dimensión internacional y relaciones con España. Madrid: Escuela Diplomática-Casa Árabe, 33-45.

Briones Martínez, I. M. (2009). El uso del velo islámico en Europa. Un conflicto de libertad religiosa y de conciencia. Especial referencia a Francia, Alemania, Reino Unido, España e Italia. Anuario de Derechos Humanos. Nueva Época, 10, 17-82.

Brooks, G. (1996). "Prólogo" y "El velo sagrado". En Un mundo bajo el velo. La vida oculta de las mujeres musulmanas. Barcelona: Debolsillo, 15-55.

Caldwell, C. (2010). La revolución europea: cómo el islam ha cambiado el viejo continente. Barcelona: Debate.

Cardini, F. (2002). Nosotros y el islam. Historia de un malentendido. Barcelona: Crítica.

Carré, O. (1997). El escollo: el estatuto de la mujer. En El islam laico. ¿Un retorno de la gran tradición? Barcelona: Bellaterra, 117-135.

Checa, F., Olmos, J. C. C. \& Garrido, Á. A. (1999). La identidad desposeída. La religión como reafirmación social en los inmigrantes. Foro hispánico: revista hispánica de Flandes y Holanda, (16), 105-116.

Corán. (2008). El Corán (edición comentada de Raúl González Bórnez). Qum (Irán), Centro de traducciones del Sagrado Corán.

Corpas, M. Á. (2015). ¿Qué es el Euroislam? Aleteia. En línea: https://es.aleteia.org/2015/10/24/ que-es-el-euroislam/.

Dassetto, F. y Bastenier, A. (1984). L'Islam transplanté. Bruselas: EPO.

De Botton, L., Taleb, F. y Puigvert Mallart, L. (2004). El velo elegido. Barcelona: El Roure.

Devji, F. (2007). Paisajes del hiyab. Militancia, moralidad, modernidad. Barcelona: Bellaterra.

Djavann, Ch. (2004). Abajo el velo. Barcelona: El Aleph.

Étienne, B. (2005). ¿Qué inquieta del islam? Barcelona: Bellaterra.

Fregosi, F. (2015). El islam en Europa. Vanguardia-Dossier, (56), 6-17.

García, A., Vives, A., Expósito, C., Pérez-Rincón, S., López, L., Torres, G. \& Loscos, E. (2012). Velos, burkas.moros: estereotipos y exclusión de la comunidad musulmana desde una perspectiva de género. Investigaciones Feministas, 2, 283-298. https://doi.org/10.5209/rev_INFE.2011. v2.38556.

Göle, N. (1991). El velo y la modernidad; Emancipación y feminidad; El velo, símbolo de islamización. En Musulmanas y modernas. Velo y civilización en Turquía. Madrid: Talasa Ediciones, 45-56, 91-97, 98-168.

Gómez García, P. (2012). Los dilemas del islam. Mirada histórica, riesgos presentes y vías de futuro. Granada: Comares.

Gómez Pérez, R. (2007). Convivir con el islam. Madrid: Ediciones Internacionales Universitarias.

Informe del Ministerio de Defensa. (2011). La influencia social del islam en la Unión Europea. Madrid: Ministerio de Defensa.

Kerrou, M. (2003). Velos islámicos y espacios públicos en el Magreb y en Europa. Anuario MED 2003. IEMed-Fundación CIDOB. En línea: http://www.iemed.org/anuari/2004/esparticles/ ekerrou.pdf.

Küng, H. (2011). El islam: historia, presente, futuro. Madrid: Trotta.

Lamrabet, A. (2014). El velo (el hiyab) de las mujeres musulmanas: entre la ideología colonialista y el discurso islámico: una visión decolonial. Tabula Rasa, (21), 31-46.

Lara, L. (2005). Debajo del hiyab. La identidad de la mujer musulmana. En línea: http://www.wayto-allah.com/es/documentos/Debajo_del_Hiyab.pdf.

Lasagabaster Herrarte, I. (2004). El velo islámico en la jurisprudencia del Tribunal Constitucional federal alemán: nota a la STC federal alemán de 24 de septiembre de 2003. Revista Vasca de Administración Pública, (69).

Llorent Bedmar, V. (2009). Utilización de signos religiosos en los centros escolares de Alemania y Reino Unido: el velo islámico. Educación XX1, (12), 97-121. 
(2013). El velo islámico: controversias ante su uso en los centros escolares españoles. Interacções, (23), 56-70. http://www.eses.pt/interaccoes

López García, B. (2013). Introducción. España y el mundo árabe-islámico: historia de una multiplicidad de relaciones y encuentros. En O. Orozco y G. Alonso (eds.), El islam y los musulmanes hoy Dimensión internacional y relaciones con España. Madrid: Escuela Diplomática-Casa Árabe, 11-28.

Maugham, W. S. (2007). El velo pintado. Barcelona: Bruguera.

Mernissi, F. (1999). El harén político. El Profeta y las mujeres. Madrid: Oriente y Mediterráneo. (2002). El hiyab desciende sobre Medina. En línea: https://www.webislam.com/ articulos/26215-el_hiyab_desciende_sobre_medina.html.

Mohorte. (2016). El velo no es sinónimo de islam. En el pasado, muchas mujeres musulmanas lo ignoraban. En línea: https://magnet.xataka.com/en-diez-minutos/no-hace-mucho-el-burkini-oel-hijab-no-eran-predominantes-en-las-sociedades-musulmanas

Moualhi, D. (2000). Mujeres musulmanas: estereotipos occidentales versus realidad social. Papers, (60), 291-304.

Motilla de la Calle, A. (2004). La libertad de vestimenta: el velo islámico. En Los musulmanes en España. Libertad religiosa e identidad cultural, 107-135.

(2004). El problema del velo islámico en Europa y en España. Anuario de Derecho Eclesiástico del Estado, (20), 87-130.

. (coord.). (2009). El pañuelo islámico en Europa. Una investigación aplicable al Derecho penal de los negocios. Barcelona: Marcial Pons.

Murtada, M. (2010). Hiyab (acerca de la vestimenta islámica). República Islámica de Irán: Fundación Cultural Oriente.

Pascual Llanos, E. (2015). "El hiyab”. Ilu. Revista de Ciencias de las Religiones, (20), 165-191.

Pérez Álvarez, M. Á. y Rebollo, M. J. (2009). El islam en la vida de lo mujer a través de los tiempos. Cauriensia, IV, 227-247.

Ramadan, T. S. (1994). Musulmans dans la laïcité, responsabilités et droits des musulmans dans les sociétés occidentales. Lyon: Tawhid.

Ramírez, Á. (2011). La trampa del velo. El debate sobre el uso del pañuelo musulmán. Madrid: Libros de la Catarata.

Rodríguez Hernández, J. A. (2006). El velo islámico. Clepsydra, (5), 167-176.

Rodríguez Quiroga, M. L. (2017). Falsos mitos de la mujer en el islam. Córdoba: Almuzara.

Ruiz Ruiz, J. J. (2011). La prohibición del velo islámico en la enseñanza pública: la perspectiva de la igualdad de género. Revista Española de Derecho Constitucional, (92), 103-140.

Serrano, F. (2011). Hiyab, ¿opresión o libertad? En línea: http://islamoriente.com/content/article/ hiyab-\%C2\%BFopresi\%C3\%B3n-o-libertad.

Stratton, A. (2009). Muhayababes (chicas con velo). El nuevo Oriente Próximo: joven, cool y devoto. Madrid: Editorial 451.

Tamayo, J. J. (2009). Las mujeres en el islam. En Islam: cultura, religión y política. Madrid: Trota, 221-257.

Tamzali, W. (2011). El burka como excusa. Terrorismo intelectual, moral y religioso contra la libertad de las mujeres. Barcelona: Saga Editorial.

Terrón Caro, T. (2012). La mujer en el islam. Análisis desde una perspectiva socioeducativa. El Futuro del Pasado, (3), 237-254.

Torres, A. (2014). El uso del hiyab a la luz de los nuevos tiempos y su relación con los Derechos Humanos. Cuadernos Judaicos, (31), 162-173.

Torres Calzada, M. K. y Pacheco, J. A. (2008). Disquisiciones sobre el velo islámico. Sevilla: ArCiBel Editores. 